\title{
CONJUGATE CONDUCTION-FREE CONVECTION HEAT TRANSFER FROM A HORIZONTAL CYLINDER
}

\author{
M. K. Bassiouny, F. M. Mahfouz, S. A. Wilson, Gamal H. Badawy \\ Mechanical Power Engineering Department, Faculty of Engineering \\ Menoufiya University, Shebin El-Kom, Egypt
}

\begin{abstract}
In this paper, the conjugate conduction-free convection heat transfer from a horizontal cylinder is numerically and experimentally investigated. In the theoretical study, the unsteady two-dimensional conduction equation for the cylindrical wall and the unsteady laminar two-dimensional governing equations for the flowing fluid are solved simultaneously using the finite-difference method. The effects of controlling parameters, such as Rayleigh number, thermal conductivity ratio and diameter ratio on heat transfer process have been investigated. The study has shown that the heat transfer rate increases with increasing Rayleigh number and thermal conductivity ratio. The study has also discussed the existence of critical radius for some Rayleigh numbers and thermal conductivity ratios. The streamlines and isotherms are plotted for some cases to show the details of the velocity and thermal fields. For verification of the numerical model, the present numerical results are compared with previously published experimental and theoretical data where good agreements were found. In the experimental study, the heat transfer from a hollow horizontal aluminum cylinder with diameter ratio of 2 and heated from its inner surface at constant temperature is investigated. The obtained experimental results are used to further assess the validity of the numerical results and acceptable agreement has been found.
\end{abstract}

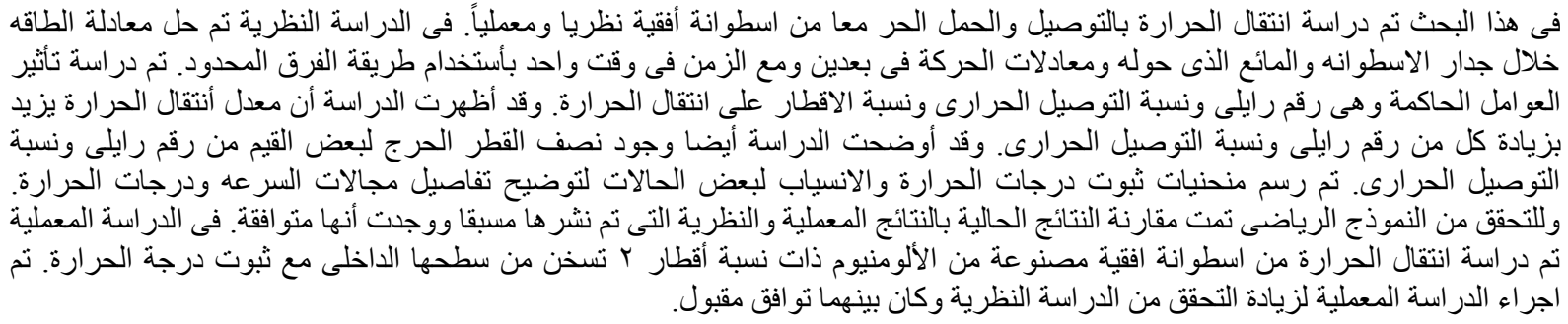

Keywords: conjugate heat transfer, free convection, heat conduction, critical radius

\section{Introduction}

Conjugate heat transfer refers to the heat transfer processes involving an interaction of conduction in a solid body and convection in the fluid surrounding it. The condition of continuity in temperature and heat flux has to be fulfilled at the solid-fluid interface. Conjugate heat transfer occurs in many important engineering devices such as heat exchangers, power plants, cooling of electrical and electronic equipments, pipe insulation systems, etc. Therefore the effect of wall conduction become very important in convection heat and must be taken into account. The conjugate heat transfer problem in which the coupled heat transfer by conduction in the solid wall and by convection in the fluid should be determined simultaneously.

Most of the previous studies have considered the heat convection from an isothermal horizontal circular cylinder. These studies were conducted either theoretically [4-10 and 15-17] or experimentally [4, 7, 11-14 and 16] or from empirical correlation [1-3].

Regarding conjugate conduction-free convection heat transfer from a horizontal cylinder few investigations were found in the literature. Sparrow and Kang [18] numerically investigated twodimensional natural convection heat transfer from insulated horizontal cylinder. They found that the use of Morgan [1] correlation gave the most accurate set of one dimensional results. In addition they reported that the standard critical radius criterion led to significant errors and should no longer be used. Moreover, they proposed the calculation of critical radius from the relation $h_{o} r_{c r} / k_{\text {ins }}=3 n /(1+n)$ where $n$ is the exponent of Rayleigh number in $\mathrm{Nu}=\mathrm{cRa}^{\mathrm{n}}$ correlation. Haldar [19] investigated numerically the conjugate heat transfer from a horizontal insulated cylinder. The study evaluated the heat losses from a 
horizontal cylinder maintained at uniform temperature and covered with a layer of insulation in the range of Grashof number from $10^{2}$ to $10^{6}$ while keeping Prandtl number constant at $\operatorname{Pr}=0.7$ and conductivity ratio (air/insulation) at 0.75 and at different insulation thicknesses. Yamamoto et al. [20] presented a numerical investigation to study the natural convection around a horizontal circular pipe coupled with heat conduction in the solid structure using a preconditioning method for solving incompressible and compressible Navier-Stokes equations. They studied the effect of heat conductivity of the pipe on natural convection. Ait Saada et al. [21] investigated natural convection from a horizontal cylinder with a porous or fibrous coating. It is indicated that porous or fibrous material may also be used as a heat transfer augmentation technique in case of selecting porous media with permeability and/or high effective thermal conductivity. Atayilmaz and Teke [22] investigated experimentally and numerically the natural convection from a horizontal cylinder with a textile coating. Heat transfer rates from bare and wrapped horizontal cylinders were compared and heat transfer enhancement was observed. Atayilmaz et al. [23] studied theoretically the problem of the natural convection heat transfer from an insulated horizontal cylinder. They investigated the effects of variable heat transfer coefficient on determining the critical radius while keeping the thermal conductivity of the insulation as constant. The study further calculated the variation of the total heat transfer from the cylinder surface as a result of variation in insulation thickness. It was found that the standard critical radius criterion led to significant errors compared to numerical results.

The classical critical radius criterion was upgraded in Sparrow [24] to account for the dependence of average heat transfer coefficient on the outer radius and on the surface to ambient temperature difference for situations where the average Nusselt number varies as a power of the Rayleigh number. Other (1976 and 1978) modifications of the critical radius have taken account of radiative heat transfer [25-27]. Balmer [26] theoretically formulated the critical radius for cylinder and sphere in case of variable convection heat transfer coefficient. They used Churchill and Chu's [3] correlation in order to develop the critical radius equation for horizontal cylinder. Kulkarni [27] formulated the critical radius for cylinder and sphere in case of constant convective heat transfer coefficient and neglecting the radiative heat transfer. The study defined a new term "cross over point" as a radius greater than the critical radius such that the heat transfer with the corresponding amount of insulating material is equal to that of the bare thermal system. It is pointed out that the cross over insulation radius is applicable when the Biot number $\left(\mathrm{hr}_{\mathrm{i}} / \mathrm{k}_{\text {ins }}\right)$ is less than 1 in a cylindrical system.

The objective of this work is to study numerically and experimentally the effect of various controlling parameters on heat transfer characteristics in case of conjugate conduction-free convection heat transfer from a horizontal cylinder placed in an unbounded fluid. The governing differential equations for the cylinder wall and adjacent flowing fluid are simultaneously solved by satisfying the continuity of the heat flux and the temperature at the interface using a finite-difference scheme.

\section{Theoretical study}

\subsection{Problem statement and governing equations}

The physical system to be considered is as shown in Fig. 1, consisting of a horizontal circular cylinder of infinite length and inner radius $\left(r_{i}\right)$ and outer radius $\left(\mathrm{r}_{\mathrm{o}}\right)$ placed in a quiescent fluid at temperature $\mathrm{T}_{\infty}$. The cylinder is heated from its inner surface at a constant temperature $\left(\mathrm{T}_{\mathrm{i}}\right)$. The cylinder is considered to be long enough such that the end effects can be neglected and the flow can be assumed two dimensional. The radiation and viscous dissipation effects are neglected and the temperature difference is assumed to have a negligible effect on the fluid properties except for the density in the buoyancy force term in the momentum equation.

Using polar cylindrical coordinate system, the governing differential equations of fluid motion and energy for flow and cylinder wall can be written in term of stream function $\psi^{\prime}$, vorticity $\Omega^{\prime}$, and temperature $\mathrm{T}$ as:

- For the cylinder wall $\left(r_{i} \leq r^{\prime} \leq r_{o}\right)$, the energy equation is reduced to:

$$
\frac{\partial T}{\partial \tau}=\alpha_{w} \nabla^{2} T
$$

- In the fluid region $\left(\mathrm{r}_{\mathrm{o}} \leq \mathrm{r}^{\prime} \leq \mathrm{r}_{\infty}\right)$ :

$$
\begin{aligned}
\frac{\partial \Omega^{\prime}}{\partial \tau}+\frac{1}{r^{\prime}} \frac{\partial \psi^{\prime}}{\partial \theta} \frac{\partial \Omega^{\prime}}{\partial r^{\prime}} & -\frac{1}{r^{\prime}} \frac{\partial \psi^{\prime}}{\partial r^{\prime}} \frac{\partial \Omega^{\prime}}{\partial \theta}=v \nabla^{2} \Omega^{\prime} \\
& +\frac{1}{\rho_{f}}\left(\frac{\partial F_{\theta}}{\partial r^{\prime}}+\frac{F_{\theta}}{r^{\prime}}-\frac{1}{r^{\prime}} \frac{\partial F_{r^{\prime}}}{\partial \theta}\right) \\
\Omega^{\prime} & =-\nabla^{2} \psi^{\prime} \\
\frac{\partial T}{\partial \tau}+\frac{1}{r^{\prime}} \frac{\partial \psi^{\prime}}{\partial \theta} \frac{\partial T}{\partial r^{\prime}} & -\frac{1}{r^{\prime}} \frac{\partial \psi^{\prime}}{\partial r^{\prime}} \frac{\partial T}{\partial \theta}=\alpha_{f} \nabla^{2} T \\
\nabla^{2} & =\frac{\partial^{2}}{\partial r^{\prime 2}}+\frac{1}{r^{\prime}} \frac{\partial}{\partial r^{\prime}}+\frac{1}{r^{\prime 2}} \frac{\partial^{2}}{\partial \theta^{2}}
\end{aligned}
$$

$\mathrm{F}_{\mathrm{r}^{\prime}}$ and $\mathrm{F}_{\theta}$ are the radial and angular components of the buoyancy force respectively and are defined as: $\mathrm{F}_{\mathrm{r}^{\prime}}=\rho_{\mathrm{f}} \mathrm{g} \beta\left(\mathrm{T}-\mathrm{T}_{\infty}\right) \cos \theta, \quad \mathrm{F}_{\theta}=-\rho_{\mathrm{f}} \mathrm{g} \beta\left(\mathrm{T}-\mathrm{T}_{\infty}\right) \sin \theta$

Engineering Research Journal, Minoufiya University, Vol. 36, No. 2, April 2013 
The velocity components $\mathrm{V}_{\mathrm{r}}{ }^{\prime}$ and $\mathrm{V}_{\theta}{ }^{\prime}$ are related to $\psi^{\prime}$ as: $\mathrm{V}_{\mathrm{r}}{ }^{\prime}=1 / \mathrm{r}^{\prime} \partial \psi^{\prime} / \partial \theta, \quad \mathrm{V}_{\theta}{ }^{\prime}=-\partial \psi^{\prime} / \partial \mathrm{r}^{\prime}$

The hydrodynamic boundary conditions are based on the no slip conditions at the wall-fluid interface and the stagnant fluid far away. While the thermal boundary conditions are the constant temperature of inner surface of the cylinder and the continuity of the heat flux and temperature at the interface. These boundary conditions can be expressed as:

$$
\begin{aligned}
\text { at } & \mathrm{r}^{\prime}=\mathrm{r}_{\mathrm{i}} \quad \mathrm{T}=\mathrm{T}_{\mathrm{i}} \\
\text { at } & \mathrm{r}^{\prime}=\mathrm{r}_{\mathrm{o}} \quad \mathrm{V}_{\mathrm{r}}^{\prime}=\mathrm{V}_{\theta}^{\prime}=\psi^{\prime}=0, \quad \Omega^{\prime}=-\nabla^{2} \psi^{\prime}, \\
& \quad\left(-\mathrm{k}_{\mathrm{w}} \partial \mathrm{T} / \partial \mathrm{r}^{\prime}\right)_{\mathrm{w} .}=\left(\mathrm{k}_{\mathrm{f}} \partial \mathrm{T} / \partial \mathrm{r}^{\prime}\right)_{\mathrm{f}} \\
\text { at } & \mathrm{r}^{\prime} \rightarrow \mathrm{r}_{\infty} \quad \mathrm{V}_{\mathrm{r}}{ }^{\prime}=\mathrm{V}_{\theta^{\prime}}=\Omega^{\prime}=0, \quad \mathrm{~T}=\mathrm{T}_{\infty}
\end{aligned}
$$

The conditions on the line of symmetry $\theta=0$ and $\pi$ can be expressed as

$$
\mathrm{V}_{\theta}^{\prime}=\partial \mathrm{V}_{\mathrm{r}}^{\prime} / \partial \theta=\psi^{\prime}=\Omega^{\prime}=\partial \mathrm{T} / \partial \theta=0
$$

Introducing the following dimensionless quantities and using modified polar coordinates $(\xi, \theta), \xi=\ln \mathrm{r}^{\prime} / \mathrm{r}_{\mathrm{i}}$ $\mathrm{r}=\mathrm{r}^{\prime} / \mathrm{r}_{\mathrm{i}}, \mathrm{V}_{\mathrm{r}}=\mathrm{V}_{\mathrm{r}}{ }^{\prime} \mathrm{r}_{\mathrm{i}} / \alpha_{\mathrm{f}}, \quad \mathrm{V}_{\theta}=\mathrm{V}_{\theta}{ }^{\prime} \mathrm{r}_{\mathrm{i}} / \alpha_{\mathrm{f}}$, $\psi=\psi^{\prime} / \alpha_{\mathrm{f}}, \quad \Omega=-\Omega^{\prime} \mathrm{r}_{\mathrm{i}}^{2} / \alpha_{\mathrm{f}}, \quad \mathrm{t}=\tau \alpha_{\mathrm{f}} / \mathrm{r}_{\mathrm{i}}^{2}$ and

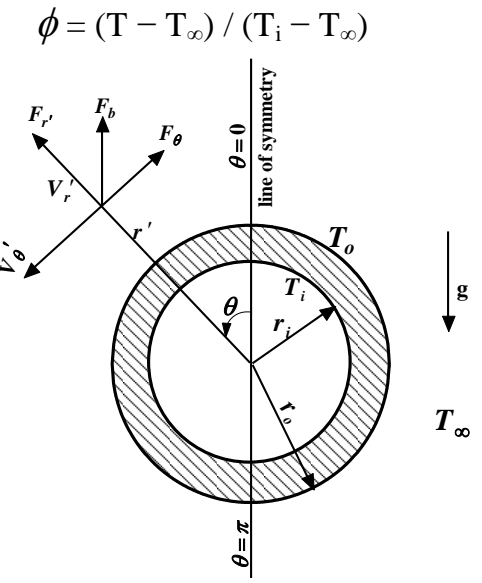

Fig.1 Coordinate system.

The governing equations can be written as:

- For the cylinder wall $\left(0 \leq \xi \leq \xi_{o}\right)$ :

$$
e^{2 \xi} \frac{\partial \phi}{\partial t}=\alpha_{R}\left(\frac{\partial^{2} \phi}{\partial \xi^{2}}+\frac{\partial^{2} \phi}{\partial \theta^{2}}\right)
$$

- For the fluid region $\left(\xi_{\mathrm{o}} \leq \xi \leq \xi_{\infty}\right)$ :

$$
\begin{gathered}
e^{2 \xi} \frac{\partial \Omega}{\partial t}=\operatorname{Pr}\left(\frac{\partial^{2} \Omega}{\partial \xi^{2}}+\frac{\partial^{2} \Omega}{\partial \theta^{2}}\right)-\frac{\partial \psi}{\partial \theta} \frac{\partial \Omega}{\partial \xi}+\frac{\partial \psi}{\partial \xi} \frac{\partial \Omega}{\partial \theta} \\
+\frac{1}{8} e^{\xi} \operatorname{Ra} \operatorname{Pr}\left(\frac{\partial \phi}{\partial \xi} \sin \theta+\frac{\partial \phi}{\partial \theta} \cos \theta\right) \\
e^{2 \xi} \Omega=\left(\frac{\partial^{2} \psi}{\partial \xi^{2}}+\frac{\partial^{2} \psi}{\partial \theta^{2}}\right) \\
e^{2 \xi} \frac{\partial \phi}{\partial t}=\left(\frac{\partial^{2} \phi}{\partial \xi^{2}}+\frac{\partial^{2} \phi}{\partial \theta^{2}}\right)-\frac{\partial \psi}{\partial \theta} \frac{\partial \phi}{\partial \xi}+\frac{\partial \psi}{\partial \xi} \frac{\partial \phi}{\partial \theta}
\end{gathered}
$$

where, $\alpha_{\mathrm{R}}=\alpha_{\mathrm{w}} / \alpha_{\mathrm{f}}$ is the thermal diffusivity ratio, $\operatorname{Pr}$ $=v / \alpha_{\mathrm{f}}$ is the Prandtl number, $\mathrm{Ra}=\mathrm{g} \beta\left(\mathrm{T}_{\mathrm{i}}-\mathrm{T}_{\infty}\right)\left(2 \mathrm{r}_{\mathrm{i}}\right)^{3} \mathrm{Pr} / \mathrm{v}^{2}$ is the Rayleigh number.

The dimensionless velocity components $\mathrm{V}_{\mathrm{r}}$ and $\mathrm{V}_{\theta}$ are now defined as: $\mathrm{V}_{\mathrm{r}}=\mathrm{e}^{-\xi} \partial \psi / \partial \theta, \mathrm{V}_{\theta}=-\mathrm{e}^{-\xi} \partial \psi / \partial \xi$

In terms of the new variables, the boundary conditions can be written as

$$
\begin{aligned}
& \text { at } \xi=0 \quad \phi=1 \\
& \text { at } \xi=\xi_{\mathrm{o}} \quad \mathrm{V}_{\mathrm{r}}=\mathrm{V}_{\theta}=\psi=0, \quad \Omega=\mathrm{e}^{-2 \xi} \partial^{2} \psi / \partial^{2} \xi \text {, } \\
& \left(\mathrm{K}_{\mathrm{R}} \partial \phi / \partial \xi\right)_{\mathrm{w}}=(\partial \phi / \partial \xi)_{\mathrm{f}} \\
& \text { at } \xi \rightarrow \infty \quad \mathrm{e}^{-\xi} \partial \psi / \partial \theta=-\mathrm{e}^{-\xi} \partial \psi / \partial \xi=\Omega=\phi=0
\end{aligned}
$$

On the line of symmetry,

$\mathrm{V}_{\theta}=\partial \mathrm{V}_{\mathrm{r}} / \partial \theta=\psi=\Omega=\partial \phi / \partial \theta=0$

where, $\mathrm{K}_{\mathrm{R}}=\mathrm{k}_{\mathrm{w}} / \mathrm{k}_{\mathrm{f}}$ is the thermal conductivity ratio.

Initial conditions (at $\mathrm{t}=0$ )

$$
\begin{aligned}
& \psi=\Omega=0 \quad \text { at } \quad \xi_{\mathrm{o}}<\xi<\infty \\
& \text { and } \phi=0 \text { at } 0<\xi<\infty
\end{aligned}
$$

\subsection{Method of solution}

The set of governing partial differential equations (5)-(8) with the corresponding boundary conditions are discretized by using the implicit finite-difference method. The first-order, backward difference is applied to descretize the time derivative while a second-order, central differences is used to descretize the spatial derivatives $(\xi, \theta)$. The set of obtained algebraic equations forming a tri-diagonal system of equations are iteratively solved by TDMA (TriDiagonal Matrix Algorithm) [28]. The acceptable value of variables is obtained when the error is equal to or less than certain prescribed error, i.e.

$$
\left|\varphi^{\mathrm{m}+1}(\xi, \theta, \mathrm{t})-\varphi^{\mathrm{m}}(\xi, \theta, \mathrm{t})\right| \leq 10^{-4}
$$

where $\varphi$ represents the functions $\phi, \psi$ and $\Omega$ and the superscript $m$ denotes the iteration order.

The number of nodes in the $\theta$ direction is taken as 180 with a step size taken as 1 degree and the number of nodes in the $\xi$ direction is 120 with a step size of 0.1 . This sets the outer boundary at a physical distance of approximately 20,000 times the inner radius of the cylinder. Such large distance is necessary to ensure that the conditions at infinity are appropriately incorporated in the numerical solution. However, the step size in the $\xi$ direction is reduced to 0.05 for cases the high Rayleigh numbers. This is due to steep variation of velocity and temperature within the thin boundary-layer in these cases. Following the start of fluid motion, very small time steps are used since the time variation of vorticity and temperature is quite fast. As time increases, the time step is gradually increased. For the sake of stability, smaller time steps are used for high Rayleigh numbers.

Solving the dimensionless form of governing equations for $\phi, \psi$ and $\Omega$, the details of flow and 
thermal fields can be determined. The dimensionless local heat fluxes $(\mathrm{Nu})$ at inner and outer surfaces of the cylinder are defined as:

$$
N u_{i}=\frac{q_{i}\left(2 r_{i}\right)}{k_{f}\left(T_{i}-T_{\infty}\right)}, \quad N u_{o}=\frac{q_{o}\left(2 r_{o}\right)}{k_{f}\left(T_{i}-T_{\infty}\right)}
$$

Where $\mathrm{q}_{\mathrm{i}}$ and $\mathrm{q}_{\mathrm{o}}$ are the local heat fluxes at inner and outer surfaces of the cylinder and are defined as:

$$
q_{i}=-\left.k_{w} \frac{\partial T}{\partial r^{\prime}}\right|_{r^{\prime}=r_{i}}, \quad q_{o}=-\left.k_{f} \frac{\partial T}{\partial r^{\prime}}\right|_{r^{\prime}=r_{o}}
$$

Using the dimensionless temperature $\phi$ together with the above definitions, one can easily deduce

$$
N u_{i}=-\left.2 K_{R} \frac{\partial \phi}{\partial \xi}\right|_{\xi=0}, \quad N u_{o}=-\left.2 \frac{\partial \phi}{\partial \xi}\right|_{\xi=\xi_{o}}
$$

The dimensionless total heat transfer rate is defined as:

$$
\overline{N u}=\frac{1}{\pi} \int_{0}^{\pi} N u d \theta
$$

It should be noted that the above definition of dimensionless local heat flux at outer surface of the cylinder is the same as the definition of local Nusselt number while the definition of dimensionless total heat transfer rate is the same as the definition of average Nusselt number. Another form for dimensionless total heat transfer rate at steady-state condition.

$$
\frac{Q}{K_{w}\left(T_{i}-T_{\infty}\right)}=\frac{\pi}{K_{R}} \overline{N u}
$$

where, Q is the total rate of heat transfer per unit length of the cylinder. In the steady-state condition the heat transferred to the cylinder from inner surface is equal to that dissipated from the outer surface.

\subsection{Theoretical results and discussion}

In order to ascertain the validity of the mathematical model as well as the numerical technique, the problem of natural convection from an isothermal solid cylinder is first studied and the obtained results are compared with the numerical and experimental results available in the literature. The values of the steady average Nusselt number at different Rayleigh numbers and at $\operatorname{Pr}=0.7$ are compared with previous works, displayed in Table 1, which shows a good agreement. Figure 2 shows a comparison at Rayleigh number $\left(\mathrm{Ra}=10^{5}\right)$ between the present results and the experimental and numerical results obtained by Kuehn and Goldstein [4] and the data obtained by Saitoh et al. [8]. The figure shows a good agreement with both references. Figure 3 indicates a comparison between present numerical temperature contours and the experimental results reported in Kuehn and Goldstein [4] for air at $\mathrm{Ra}=10^{5}$ and a very good agreement can be observed.

In the following subsections the effect of the controlling parameters on the temperature profiles and heat transfer at thermal diffusivity ratio of 4 is investigated. The heat is transferred from inner surface of the cylinder to outer surface by conduction and then dissipated to surrounding by convection. Figure 4, which represents the time development of $\overline{\mathrm{Nu}}$ along inner and outer walls at $\mathrm{Ra}=10^{3}, \mathrm{Pr}=0.7$, $\mathrm{d}_{\mathrm{o}} / \mathrm{d}_{\mathrm{i}}=2$ and $\mathrm{K}_{\mathrm{R}}=4$. The figure shows that the rate of total heat rejected (in terms of $\overline{\mathrm{Nu}_{\mathrm{O}}}$ ) from the outer wall increases with time, while that pumped into the cylinder through the inner wall (in terms of $\overline{\mathrm{Nu}_{\mathrm{i}}}$ ) decreases until they become almost equal at the steady-state.

Table 1. Comparison between present steady values of $\overline{\mathrm{Nu}}$ with published results.

\begin{tabular}{|c|c|c|c|c|}
\hline \multirow{2}{*}{ Ra } & \multicolumn{4}{|c|}{$\overline{\mathbf{N u}}$} \\
\cline { 2 - 5 } & $\begin{array}{c}\text { Present } \\
\text { study }\end{array}$ & $\begin{array}{c}\text { Ref. } \\
{[21]}\end{array}$ & $\begin{array}{c}\text { Ref. } \\
{[4]}\end{array}$ & $\begin{array}{c}\text { Ref. } \\
{[1]}\end{array}$ \\
\hline $10^{3}$ & 3.016 & 2.9754 & 3.09 & 3.11 \\
\hline $10^{4}$ & 4.85 & 4.7638 & 4.94 & 4.80 \\
\hline $10^{5}$ & 7.996 & 7.8897 & 8.00 & 8.54 \\
\hline
\end{tabular}

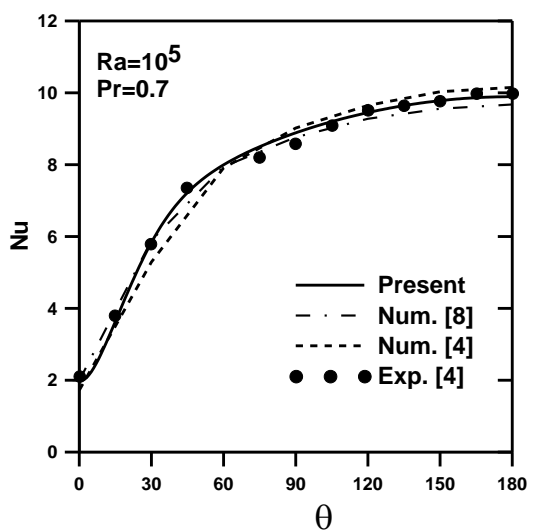

Fig. 2. Comparison between present results for $\mathrm{Nu}$ with previous numerical and experimental results.

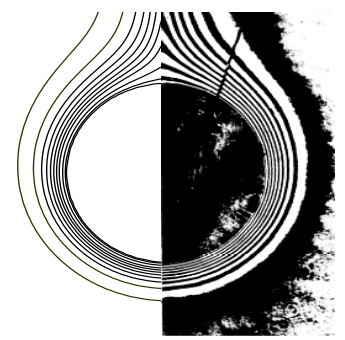

Fig. 3. Comparison of present temperature contours (left) with previous experimental results (right) of Ref.[4] for air, $\operatorname{Pr}=0.7, \operatorname{Ra}=10^{5}$.

\subsubsection{Effect of Rayleigh number (Ra)}

The effect of Rayleigh number on heat transfer is studied up to $10^{5}$. Figure 5 shows the time variation of $\overline{\mathrm{Nu}_{\mathrm{o}}}$ at $\mathrm{Pr}=0.7, \mathrm{~d}_{\mathrm{o}} / \mathrm{d}_{\mathrm{i}}=2$ and $\mathrm{K}_{\mathrm{R}}=4$ for 
different values of Ra. The figure illustrates that the total rate of heat transfer (in terms of $\overline{\mathrm{Nu}_{\mathrm{o}}}$ ) is initially low due to low temperature gradient near the outer surface. As the time goes considerable increase of heat transfer rate occurs due to the heat conduction through the cylinder wall. After that the heat transfer rate decreases due to increase of thickness of thermal layer near the surface till reaching a minimum at a certain time. Beyond this time, the buoyancy force starts developing, causing the fluid to set in motion and hence transition from conduction dominated mode to the convection dominated mode takes place. The transition from conduction to convection for this case takes the form of an overshoot. At later times, the buoyancy force effect dominates and heat transfer rate gradually approaches its final steady value. The time needed to reach steady-state depends on Ra. The higher the Rayleigh number the faster and stronger the effect of convection and hence the higher the value of total rate of heat transfer and the smaller the time needed to reach steady-state.

The steady-state local heat flux (in terms of $\mathrm{Nu}$ ), temperature $(\phi)$ distributions at the outer surface are shown in Figs. 6 and 7, respectively for $\operatorname{Pr}=0.7$, $\mathrm{d}_{\mathrm{o}} / \mathrm{d}_{\mathrm{i}}=2$ and $\mathrm{K}_{\mathrm{R}}=4$ and different values of $\mathrm{Ra}$. As can be seen in Fig. 6, for all Ra, the maximum heat flux occurs at the bottom of the cylinder $\left(\theta=180^{\circ}\right)$ due to high temperature gradient. The heat flux decreases monotonically with $\theta$ and attains a minimum at the top $\left(\theta=0^{\circ}\right)$. This variation in local heat flux reflects the local distribution of temperature, which takes its smallest value at the bottom $\left(\theta=180^{\circ}\right)$ and increases monotonically with $\theta$ and attains a maximum at the top $\left(\theta=0^{\circ}\right)$ as shown in Fig. 7.

Figures 8(a) and (b) show the steady-state calculated streamlines (left) and isotherms (right) patterns at $\operatorname{Pr}=0.7, \mathrm{~d}_{0} / \mathrm{d}_{\mathrm{i}}=2$ and $\mathrm{K}_{\mathrm{R}}=4$ for the cases of $\mathrm{Ra}=10^{3}$ and $10^{4}$. Since the flow and thermal fields are symmetric about $\theta=0$, only one-half of the field is shown. The isotherms patterns show the temperature around the cylinder and in the wall of the cylinder. In the two figures the surrounding fluid around the cylinder is heated, and a thermal boundary-layer and a thermal plume are formed. The isotherms move upward at the top of the cylinder (region of the plume) while continue adhering to it at the bottom. On the other hand, temperature distributions are observed between the inner wall and the outer surface of the cylinder in every case. Temperature contours around and in the wall of the cylinder are connected at the outer surface. The upper face of the cylinder tends to be more heated than the other region, because of heat released from the cylinder due to convection. The thermal energy in the wall of the cylinder is transferred to the surrounding fluid through the cylinder surface. Since the buoyancy effect induces a thermal plume upon the cylinder, larger convection in the plume provides higher heat removal from the cylinder. These figures show the obvious fact that the boundary layer becomes thin with increasing $\mathrm{Ra}$ and higher heat removal occurs when a higher $\mathrm{Ra}$ is considered.

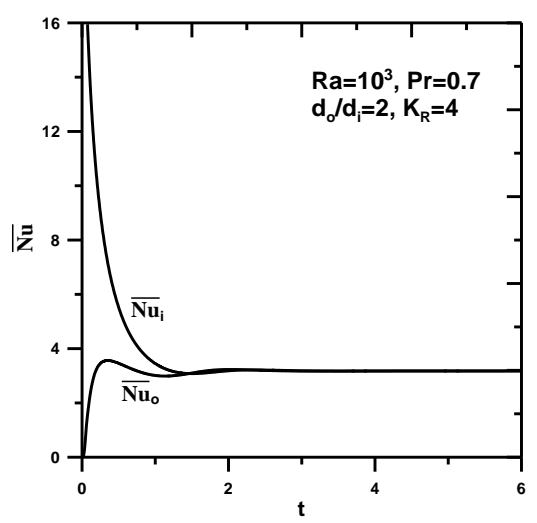

Fig. 4. The time variation of the average $\mathrm{Nu}$ of inner and outer surfaces of the cylinder at $\operatorname{Ra}=10^{3}, \operatorname{Pr}=0.7$, $\mathrm{d}_{\mathrm{o}} / \mathrm{d}_{\mathrm{i}}=2$ and $\mathrm{K}_{\mathrm{R}}=4$.

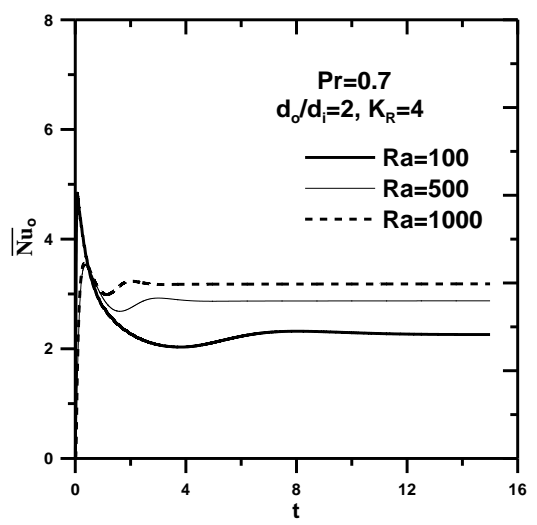

Fig. 5. The time variation of the average $\mathrm{Nu}$ of the outer surface for different values of Ra.

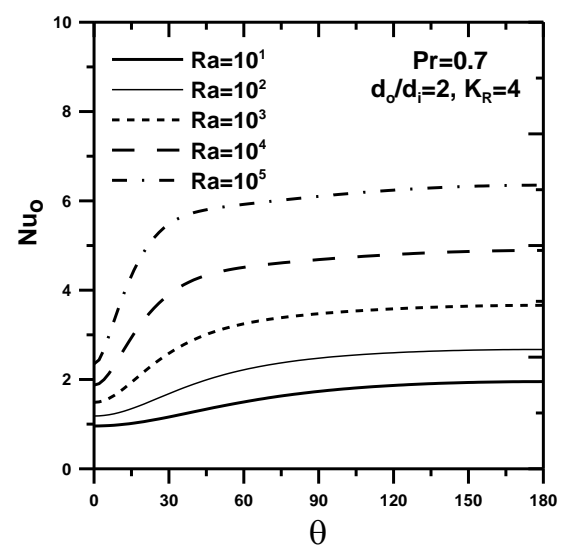

Fig. 6. Distribution of the steady $\mathrm{Nu}$ along the outer surface for different Ra.

Engineering Research Journal, Minoufiya University, Vol. 36, No. 2, April 2013 


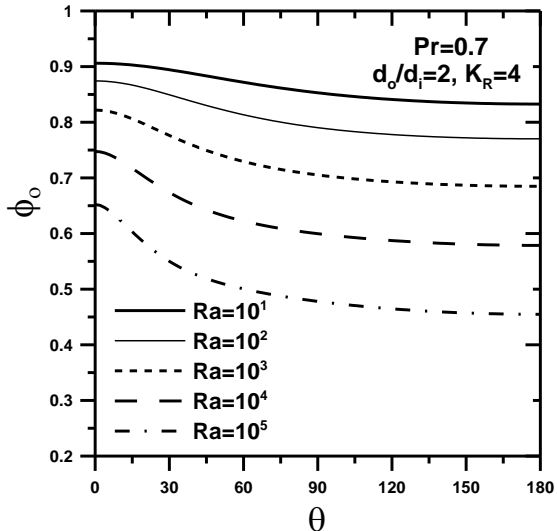

Fig. 7. Distribution of the steady local temperature of the outer surface for different Ra.

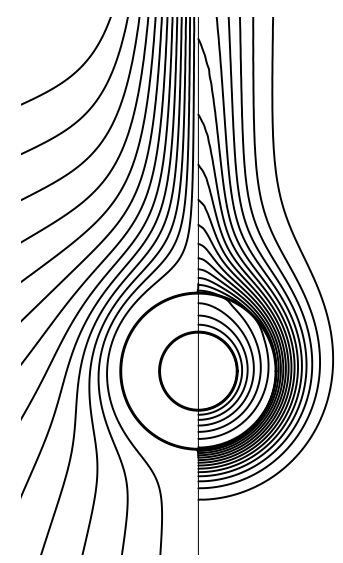

$$
\Delta \psi=2.0 \quad \Delta \phi=0.05
$$

(a)

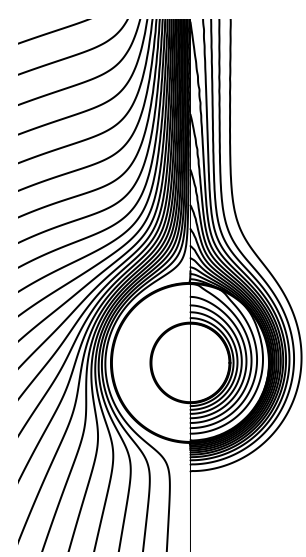

$\Delta \phi=0.05$
Fig. 8. Computed streamlines and isotherms for $\operatorname{Pr}=0.7, \mathrm{~d}_{0} / \mathrm{d}_{\mathrm{i}}=2$ and $\mathrm{K}_{\mathrm{R}}=4$ at: (a) $\mathrm{Ra}=10^{3}$, (b) $\mathrm{Ra}=10^{4}$

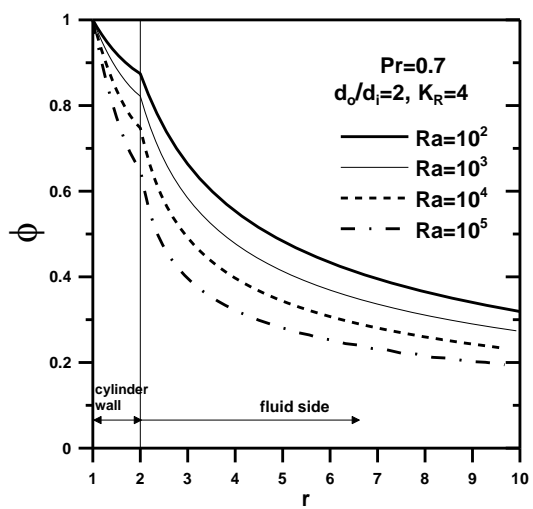

Fig. 9 Distribution of the steady temperature with radius along $\theta=0$ for different $\mathrm{Ra}$.

Figure 9 shows the calculated temperature distribution along radial direction at $\theta=0$ for different values of $\mathrm{Ra}$. Since the temperature on the outer surface of the cylinder decreases according to the increase in Rayleigh number, as shown in Fig. 7, the temperature distributions along radial direction at $\theta=0$ is also influenced by the temperature on the outer surface of the cylinder.

\subsubsection{Effect of diameter ratio $\left(d_{0} / d_{i}\right)$}

Due to the relatively small heat transfer coefficients in natural convection, the external convective resistance is high relative to the conductive resistance in the case of low thermal conductivity ratio (cylinder wall is insulation) the critical radius usually exists. Figures 10 and 11 have been prepared to compare the heat transfer data from the present study with the numerical results of Sparrow and Kang [18] at $\operatorname{Pr}=0.7$ and $K_{R}=2$ for $\mathrm{Ra}=20$ and 1000. This comparison provides a further check for the accuracy of the present numerical computational scheme and confirms consistency with the findings of Sparrow and Kang [18].

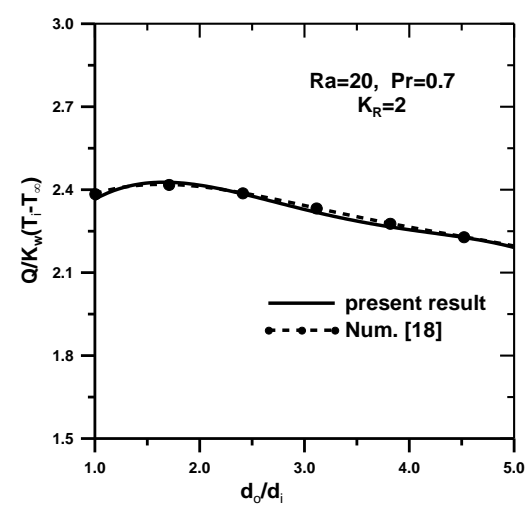

Fig. 10. The steady rate of heat transfer distribution with $d_{o} / d_{i}$ at $R a=20, \operatorname{Pr}=0.7, K_{R}=2$.

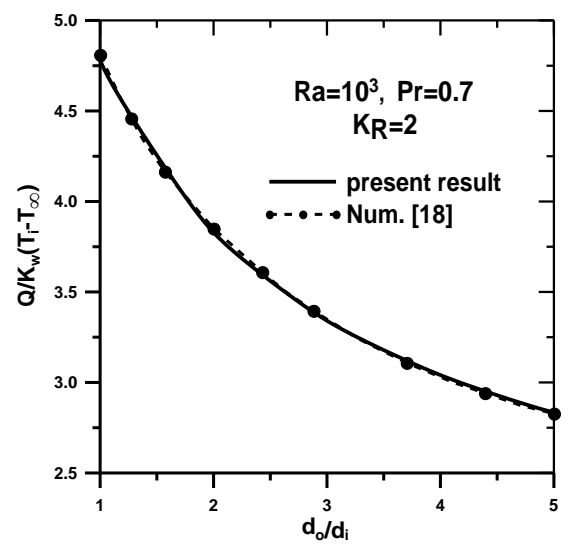

Fig. 11. Variation of the steady rate of heat transfer with $\mathrm{d}_{\mathrm{o}} / \mathrm{d}_{\mathrm{i}}$ at $\mathrm{Ra}=10^{3}, \mathrm{Pr}=0.7, \mathrm{~K}_{\mathrm{R}}=2$.

Figures 10-16 indicate the variation of the dimensionless steady rate of heat transfer from the cylinder $\left(\mathrm{Q} / \mathrm{K}_{\mathrm{w}}\left(\mathrm{T}_{\mathrm{i}}-\mathrm{T}_{\infty}\right)\right)$ with the diameter ratio $\left(\mathrm{d}_{\mathrm{o}} / \mathrm{d}_{\mathrm{i}}\right)$. Figures $10-12$ are made for $\mathrm{K}_{\mathrm{R}}=2$, with 
$\mathrm{Ra}=20,10^{2}$ and $10^{3}$, while Figs. $13-15$ are made for $K_{R}=4$ and for the same values of Ra. Figure 16 is done for $\mathrm{K}_{\mathrm{R}}=100,500$ at $\mathrm{Ra}=10^{3}$. In this regard, it may be noted that if there is a maximum at which the slop of the curve is horizontal, that maximum corresponds to the critical radius of the insulation. In figures 10, 13-15, all of the curves display a critical radius. At radius less than critical radius, the convective resistance decreases and the conductive resistance increases but the total resistance decreases and the heat rate therefore increases with the addition of insulation. This trend continues until the outer radius of the insulation corresponds to the critical radius. The trend is desirable for electrical current flow through a wire, since the addition of electrical insulation would aid in transferring heat dissipated in the wire to the surroundings. Conversely, at radius greater than critical radius, any addition of insulation would increase the conductive resistance and decrease the convective resistance but the total resistance increases and therefore decreases the heat rate. This behavior would be desirable for stream flow through a pipe, where insulation is added to reduce heat loss to the surroundings.

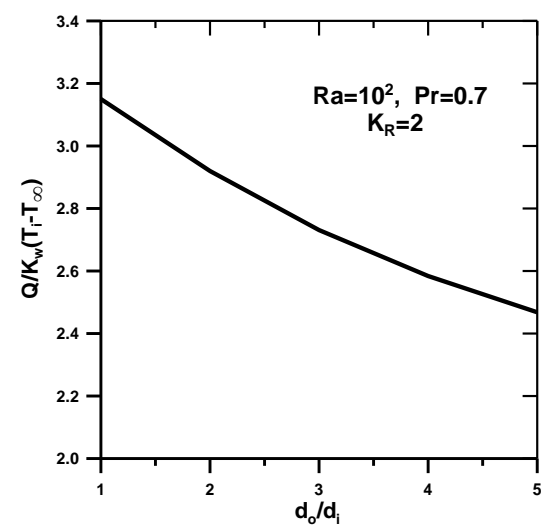

Fig. 12. Variation of the steady rate of heat transfer with $\mathrm{d}_{\mathrm{o}} / \mathrm{d}_{\mathrm{i}}$ at $\mathrm{Ra}=10^{2}, \mathrm{Pr}=0.7, \mathrm{~K}_{\mathrm{R}}=2$.

In Figs. 11 and 12, no critical radii are displayed since for the relatively low $\mathrm{K}_{\mathrm{w}}$ value implied by $\mathrm{K}_{\mathrm{w}} / \mathrm{K}_{\mathrm{f}}=2$, the external convective resistance associated with $\mathrm{Ra}=10^{2}$ and $10^{3}$ are too small to trigger the conduction-convection competition needed for the attainment of the critical radius. In Fig. 16, the heat rate increases with the increase of $\mathrm{d}_{\mathrm{o}} / \mathrm{d}_{\mathrm{i}}$ due to the relatively high thermal conductivity of the wall $\left(\mathrm{K}_{\mathrm{R}}=100\right.$ and 500$)$, thereby the conductive resistance increases with $d_{o} / d_{i}$ while the convective resistance decreases but the total resistance decreases which increases the heat rate continuously with $\mathrm{d}_{\mathrm{o}} / \mathrm{d}_{\mathrm{i}}$. From all Figures, the critical radius is a strong function of the thermal conductivity ratio $\left(\mathrm{K}_{R}\right)$ where the critical radius increases (at same $R a$ ) as $K_{R}$ increases. The increase reflects the tendency toward diminished conductive resistance at larger $K_{R}$ and the greater thickness of insulation that counteracts this tendency.

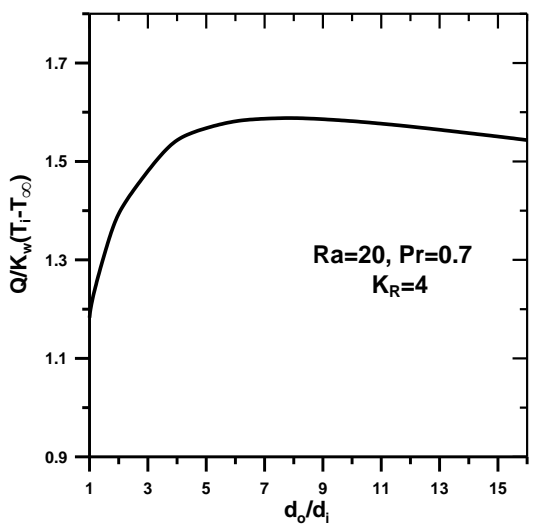

Fig. 13. Variation of the steady rate of heat transfer with $\mathrm{d}_{\mathrm{o}} / \mathrm{d}_{\mathrm{i}}$ at $\mathrm{Ra}=20, \operatorname{Pr}=0.7, \mathrm{~K}_{\mathrm{R}}=4$.

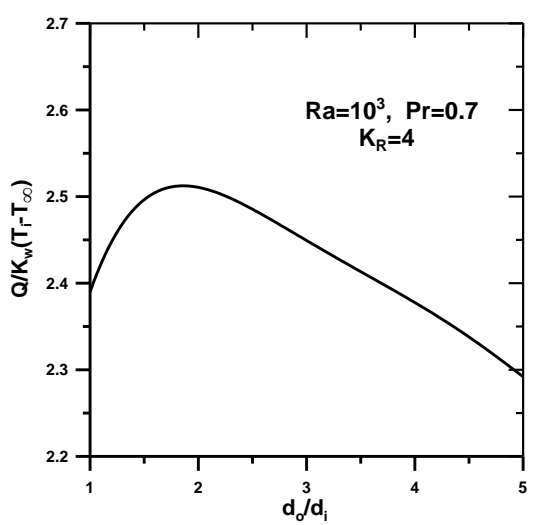

Fig. 14. Variation of the steady rate of heat transfer with $\mathrm{d}_{\mathrm{o}} / \mathrm{d}_{\mathrm{i}}$ at $\mathrm{Ra}=10^{3}, \operatorname{Pr}=0.7, \mathrm{~K}_{\mathrm{R}}=4$.

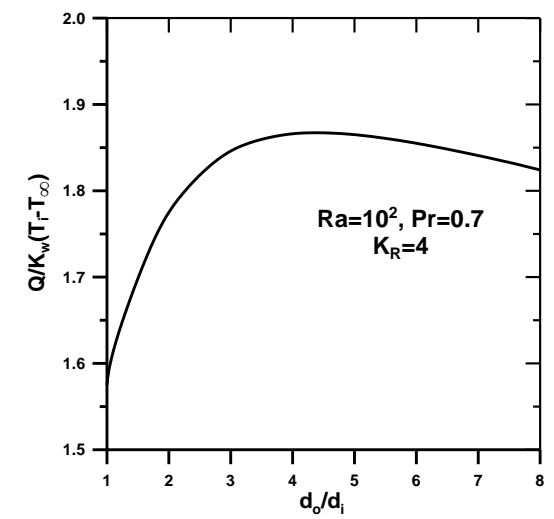

Fig. 15. Variation of the steady rate of heat transfer with $\mathrm{d}_{\mathrm{o}} / \mathrm{d}_{\mathrm{i}}$ at $\mathrm{Ra}=10^{2}, \operatorname{Pr}=0.7, \mathrm{~K}_{\mathrm{R}}=4$.

Engineering Research Journal, Minoufiya University, Vol. 36, No. 2, April 2013 


\subsubsection{Effect of thermal conductivity ratio $\left(K_{R}\right)$}

The effect of thermal conductivity ratio on heat transfer is studied at 2, 4, 100 and 500 for $\mathrm{Ra}=10^{3}$, $\operatorname{Pr}=0.7$ and $\mathrm{d}_{\mathrm{o}} / \mathrm{d}_{\mathrm{i}}=2$. Figure 17 shows the steady local $\mathrm{Nu}$ distribution along the outer surface of the cylinder for the four values of $K_{R}$. The local $\mathrm{Nu}$ distributions are influenced by the temperature on the outer surface as can be observed in Fig.18. A lower temperature on the outer surface due to lower heat conductivity of the cylinder wall results in a lower $\mathrm{Nu}$ (or heat flux). It can be also inferred from Fig. 17 that the steady heat transfer rate from the outer surface (represented by area under curve) of the cylinder increases as $K_{R}$ increases as a result of increasing the temperature at outer surface. The distribution of the steady local temperature on outer surface of the cylinder for the four values of $K_{R}$ presented in Fig. 18 shows that the temperature at outer surface is increased as $K_{R}$ increases due to the increase of heat conduction in the cylinder wall.

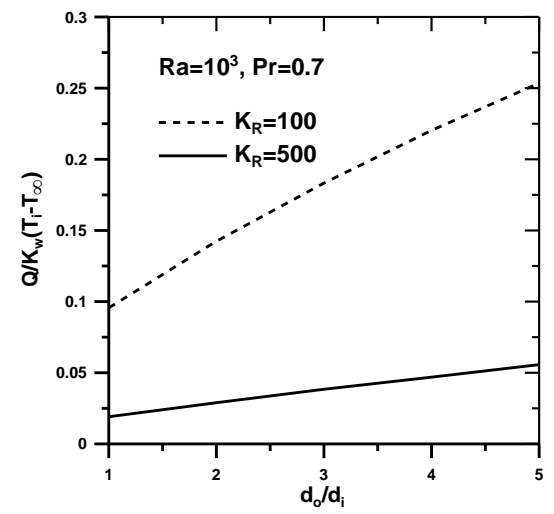

Fig. 16. Variation of the steady rate of heat transfer with $\mathrm{d}_{\mathrm{o}} / \mathrm{d}_{\mathrm{i}}$ at $\mathrm{Ra}=10^{3}, \operatorname{Pr}=0.7, \mathrm{~K}_{\mathrm{R}}=100,500$.

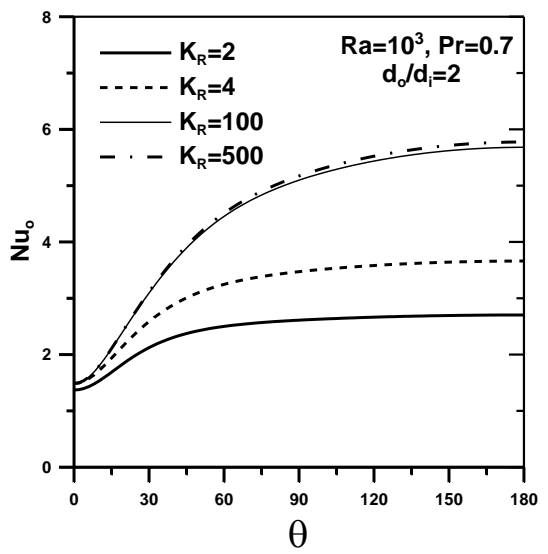

Fig. 17. Distribution of the steady Nu along the outer surface for different $K_{R}$.
Figure 19 Shows the calculated radial temperature distribution along $\theta=0$ for different values of thermal conductivity ratio. The temperature on the outer surface of the cylinder increases due to the increase of $\mathrm{K}_{\mathrm{R}}$. Moreover, the temperature distributions along $\theta=0$ are also influenced by the temperature on the outer surface of the cylinder. From this figure one can say that the higher heat conduction occurs when a higher heat conductivity of the cylinder wall is specified.

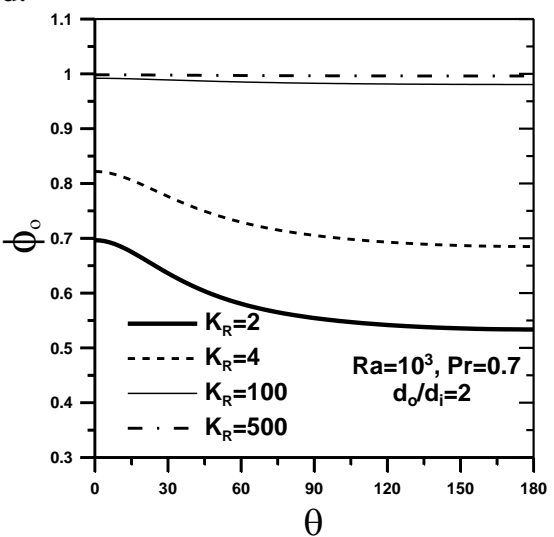

Fig. 18. Distribution of the steady local temperature on outer surface of the cylinder for different $K_{R}$.

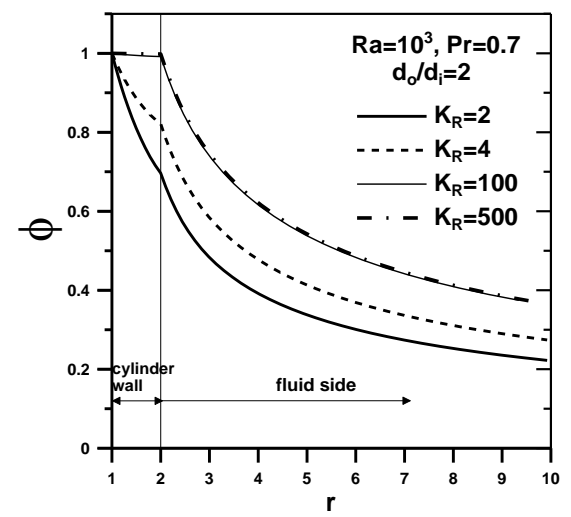

Fig. 19. Distribution of the steady temperature with $r$ at $\theta=0$ for different $K_{R}$.

\section{Experimental study}

The objective of the experimental work is to study the effect of Rayleigh number on the heat transfer from the horizontal cylindrical tube, taking into account the thickness of the cylinder.

\subsection{Experimental apparatus}

The experimental apparatus used is shown diagrammatically in Fig. 20. It consists essentially of a hollow horizontal circular cylinder (test section) rested on a stand to lift it away from the ground level. The cylinder made from aluminum material of 400 $\mathrm{mm}$ length and with $30 \mathrm{~mm}$ and $60 \mathrm{~mm}$ inside and outside diameters respectively. An electric heater of 
500 Watt is centered inside the cylinder to maintain the required uniform surface temperature. Four temperature. At the mid length of cylinder, four notches were formed in circumferential direction with $60^{\circ}$ apart at angles of $0^{\circ}, 60^{\circ}, 120^{\circ}$, and $180^{\circ}$. Four thermocouples are buried and brazed in these notches on the outer surface and another four thermocouples are placed in these notches at a distance $(\delta)$ of $2.5 \mathrm{~mm}$ from the outer surface of cylinder as shown in Fig. 21. T-type thermocouples calibrated with reference thermometer were used. The cylinder can turn around its axis of symmetry to measure the circumferential temperature every $30^{\circ}$. The readings of the thermocouples were taken by means of a pre-calibrated digital temperature reader. The ambient air temperature was measured by a mercury-in-glass thermometer. To minimize the end losses, two pieces of insulating material made of glass wool are placed on the cylinder endpoints. The input electric power to the heater was controlled by AC voltage regulator (variac), the electric power is disconnected from the heater automatically by the temperature controller device when the required temperature on the inner surface of cylinder is reached. The experiments were conducted in a closed room $(3000 \times 2500 \times 3000 \mathrm{~mm})$ to prevent air currents and allow the air to circulate freely around the cylinder.

\subsection{Experimental procedure}

The ambient temperature in the closed room was fixed at $\mathrm{T}_{\infty}=32{ }^{\circ} \mathrm{C}$. Input power was controlled by $\mathrm{AC}$ variac for the desired temperature at inner surface of cylinder. The thermocouples of the inner surface in the axial direction and the thermocouples of the outer surface and at a distance of $2.5 \mathrm{~mm}$ from the outer surface in the circumferential direction (mid length of cylinder) are used for measuring the inner surface and circumferential temperatures respectively. The steady-state condition is considered when variation of all temperatures especially the inner surface temperature stays in the range of \pm 0.1 $0.2{ }^{\circ} \mathrm{C}$ for 20 minutes. The steady-state condition for each experiment was achieved after 2.5-3 hours approximately. When the steady-state condition was established, the readings of all thermocouples were recorded. The experiments were repeated by increasing the inner surface temperature where the temperature difference between the inner surface of the cylinder and the ambient $\left(\Delta \mathrm{T}=\mathrm{T}_{\mathrm{i}}-\mathrm{T}_{\infty}\right)$ is varied from $10{ }^{\circ} \mathrm{C}$ to $41.9{ }^{\circ} \mathrm{C}$ for each experiment.

\subsection{Evaluation of the measurements}

The dimensional analysis generally shows that natural convection heat transfer from horizontal cylinders depends on Rayleigh numbers (Ra) and thermocouples mounted in the axial direction of the inner surface of the cylinder to measure the axial Prandtl numbers (Pr). The readings of the measuring instruments are used to estimate the values of the temperatures and the calculated parameters as follows:

$$
\mathrm{Ra}=\frac{\mathrm{g} \beta\left(\mathrm{T}_{\mathrm{i}}-\mathrm{T}_{\infty}\right)\left(2 \mathrm{r}_{\mathrm{i}}\right)^{3}}{v^{2}} \operatorname{Pr}
$$

The air thermo physical properties $(\operatorname{Pr}, v, \beta)$ were evaluated at the mean film temperature $\left(\mathrm{T}_{\mathrm{f}}\right)$ where $\mathrm{T}_{\mathrm{f}}=\left(\mathrm{T}_{\mathrm{i}}+\mathrm{T}_{\infty}\right) / 2, \beta=1 /\left(\mathrm{T}_{\mathrm{f}}+273\right)$, Ref. [29].

Table 2 shows the values of the Rayleigh numbers corresponding to the values of the temperature differences $\left(\Delta T=T_{i}-T_{\infty}\right)$.

The local heat flux (q) at the outer surface of the cylinder can be calculated as follow;

$$
q_{o}=-\left.k_{f} \frac{\partial T}{\partial r^{\prime}}\right|_{r_{o}}=-k_{f} \frac{T_{o+\delta}-T_{o}}{\delta}
$$

$\mathrm{T}_{\mathrm{o}+\delta}-\mathrm{T}_{\mathrm{o}}$ is the temperature difference across the distance $(\delta)$ see Fig. 21.

The dimensionless local heat flux (Nusselt number $\mathrm{Nu})$ at outer surface of the cylinder is defined as

$$
N u_{o}=\frac{q_{o}\left(2 r_{o}\right)}{k_{f}\left(T_{i}-T_{\infty}\right)}=-\frac{\left(2 r_{o}\right)}{\left(T_{i}-T_{\infty}\right)} \frac{T_{o+\delta}-T_{o}}{\delta}
$$

\subsection{Uncertainty analysis}

Generally, the accuracy of the experimental results depends upon the accuracy of the individual measuring instruments and the manufacturing accuracy of the cylinder tube. Amongst many error analysis methods, uncertainty analysis method which is firstly proposed by Kline and McClintock [30] is the most widely used for experimental studies. The independent variables that may cause error in the experiments are length measurements, cylinder surfaces and environment temperatures. The uncertainty for length measurements are $\pm 0.05 \mathrm{~mm}$, $\pm 0.05{ }^{\circ} \mathrm{C}$ for cylinder surfaces temperatures and \pm 0.5 ${ }^{\circ} \mathrm{C}$ for ambient air temperature. The maximum uncertainties of the $\mathrm{Ra}$ and $\overline{N u}_{o}$ calculated from the correlation of Kline and McClintock [30] are $\pm 1.923 \%$ and $\pm 2.351 \%$ respectively.

\subsection{Experimental results}

Figures 22 and 23 illustrate the effect of the Rayleigh number on the local heat flux (in terms of $\mathrm{Nu}_{\mathrm{o}}$ ) and temperature at the outer surface of the cylinder. Rayleigh number was varied by increasing the temperature difference between the inner surface of the cylinder and the ambient air. It can be seen that increasing of $\mathrm{Ra}$ increases the temperature and the local heat flux as mentioned in the theoretical study. Since the thermal conductivity of the cylinder is high, the variation in the temperature on the outer surface 
is small at any value of the Rayleigh number. Though the trend of this variation is similar to that obtained in the numerical results as shown in Fig. 18.

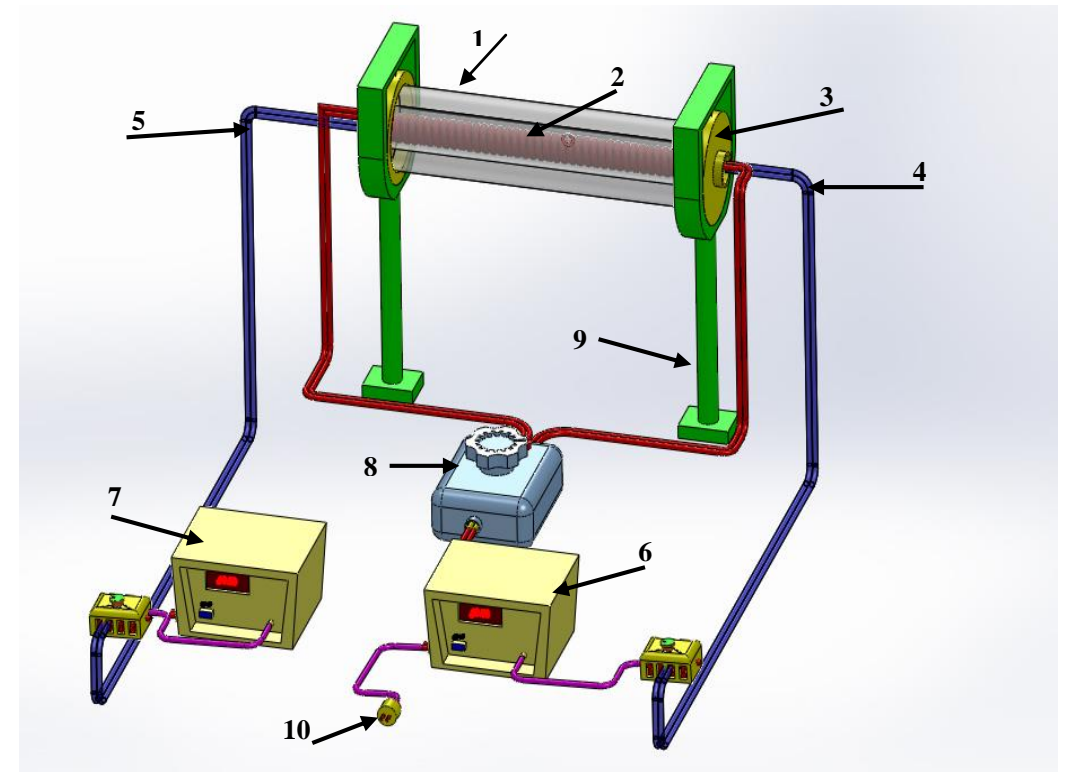

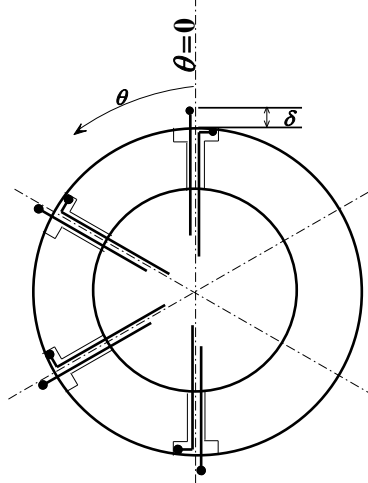

Fig. 21. Distribution of the thermocouples in the circumferential direction.

Fig. 20. Schematic diagram of the experimental apparatus

(1) test cylinder; (2) heater; (3) insulating material made of glass wool; (4) thermocouples in the inner surface of the cylinder (4 pieces) ; (5) thermocouples in circumferential direction of the outer surface of the cylinder $(8$ pieces); (6) temperature controller device; (7) digital temperature reader; (8) voltage regulator (variac); (9) stand; (10) AC power supply.

Table 2. The values of Rayleigh numbers corresponding to the values of temperatures differences.

\begin{tabular}{|c|c|c|c|c|c|}
\hline$\Delta \mathrm{T}\left({ }^{\circ} \mathrm{C}\right)$ & 10 & 15 & 20 & 30 & 41.9 \\
\hline $\mathrm{Ra}$ & $2.39 \times 10^{4}$ & $3.58 \times 10^{4}$ & $4.77 \times 10^{4}$ & $7.16 \times 10^{4}$ & $1 \times 10^{5}$ \\
\hline
\end{tabular}

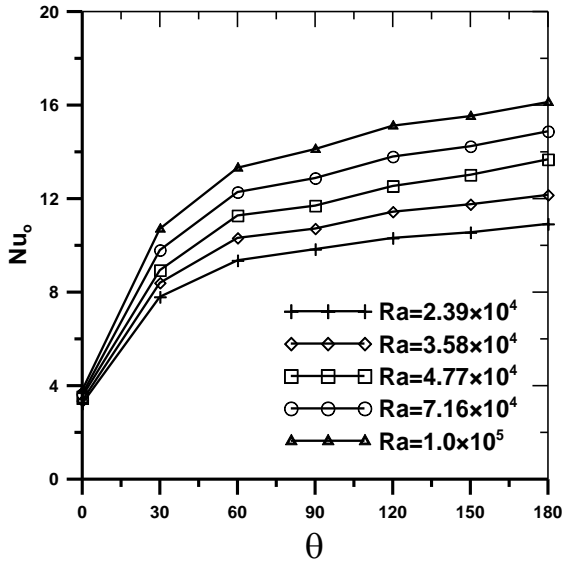

Fig. 22. Distribution of the $\mathrm{Nu}_{\mathrm{o}}$ along the outer surface for different Ra.

In order to further assess the numerical results some comparisons with the present experimental data are presented in Table 3 and Fig. 24. Table 3 shows the values of steady $\overline{N u}_{o}$ at different $\mathrm{Ra}$ and comparison with theoretical results. Figure 24 shows a comparison between experimental and theoretical results for distribution of the local $\mathrm{Nu}$ along the outer surface at $\mathrm{Ra}=10^{5}$. The comparisons show a reasonable agreement.

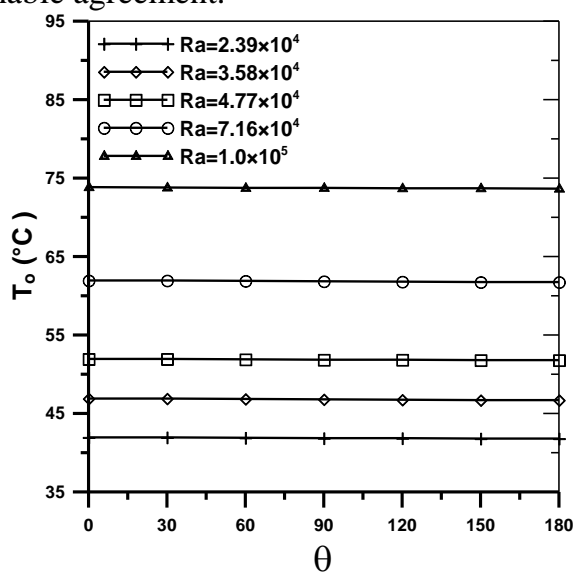

Fig. 23. Distribution of the local temperature of the outer surface at different $\mathrm{Ra}$. 


\section{Conclusions}

The problem of conjugate conduction-free convection heat transfer analysis from a horizontal cylinder is investigated. The effects of controlling parameters $\left(\mathrm{Ra}, \mathrm{d}_{\mathrm{o}} / \mathrm{d}_{\mathrm{i}}\right.$ and $\left.\mathrm{K}_{\mathrm{R}}\right)$ on heat transfer are studied. The steady-state heat transfer rate increases

Table 3. The experimental values of steady $\overline{N u}_{o}$ and comparison with theoretical results.

\begin{tabular}{|l|c|c|}
\hline $\mathrm{Ra}$ & $\overline{N u_{o}}($ Exp.) & $\overline{N u}_{o}$ (Theor. $)$ \\
\hline $2.39 \times 10^{4}$ & 8.863 & 9.34 \\
\hline $3.58 \times 10^{4}$ & 9.737 & - \\
\hline $4.77 \times 10^{4}$ & 10.529 & 11.045 \\
\hline $7.16 \times 10^{4}$ & 11.646 & - \\
\hline $1.0 \times 10^{5}$ & 12.677 & 13.26 \\
\hline
\end{tabular}

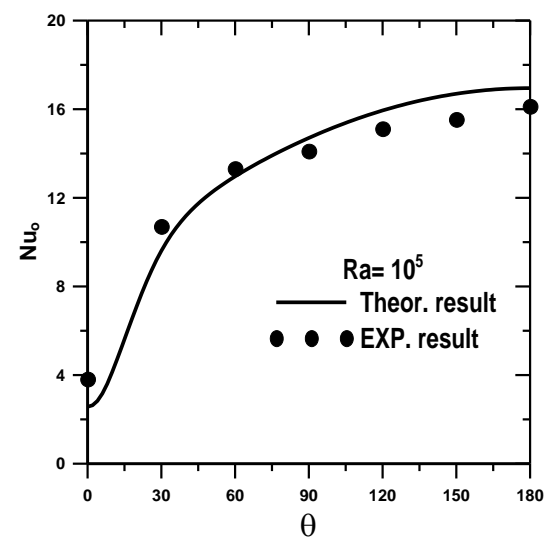

Fig. 24. Comparison of experimental and theoretical local $\mathrm{Nu}_{\mathrm{o}}$ at $\mathrm{Ra}=10^{5}$

with increasing both, the Rayleigh number and thermal conductivity ratio. Results for the critical radius were also obtained at some values of $\mathrm{Ra}$ and $K_{R}$. The critical radius was found to be sensitive to both the Rayleigh number and the thermal conductivity ratio. The streamlines and isotherms are plotted for some of cases to show the details of the velocity and thermal fields. Experimentally determined heat fluxes with different values of $\mathrm{Ra}$ agree with the present numerical results.

\section{Nomenclature}

$r_{i}, r_{o} \quad$ inner and outer radii of cylinder

$\mathrm{d}_{\mathrm{i}}, \mathrm{d}_{\mathrm{o}} \quad$ inner and outer diameters of cylinder

g gravitational acceleration

$\mathrm{T}$ temperature

$\mathrm{r}$ dimensionless radial coordinate $\left(=\mathrm{r}^{\prime} / \mathrm{r}_{\mathrm{i}}\right)$

$\mathrm{t}$ dimensionless time $\left(=\tau \alpha_{\mathrm{f}} / \mathrm{r}_{\mathrm{i}}^{2}\right)$

$\mathrm{k}$ thermal conductivity

$\mathrm{K}_{\mathrm{R}} \quad$ thermal conductivity ratio $\left(=\mathrm{k}_{\mathrm{w}} / \mathrm{k}_{\mathrm{f}}\right)$

Pr Prandtl number $\left(=v / \alpha_{f}\right)$

$\mathrm{Ra} \quad$ Rayleigh number $\left(=\mathrm{g} \beta\left(\mathrm{T}_{\mathrm{i}}-\mathrm{T}_{\infty}\right)\left(2 \mathrm{r}_{\mathrm{i}}\right)^{3} \mathrm{Pr} / v^{2}\right)$

$\mathrm{q}$ heat flux

$\mathrm{Nu}$ dimensionless local heat flux
$\begin{array}{ll}\overline{\mathrm{Nu}} & \text { dimensionless total heat transfer rate } \\ \mathrm{Q} & \text { heat transfer rate per unit length } \\ \mathrm{V}_{\mathrm{r}}, \mathrm{V}_{\theta} & \text { radial and angular velocity components }\end{array}$

Greek symbols

$\rho$ density

$\alpha \quad$ thermal diffusivity

$\alpha_{\mathrm{R}} \quad$ thermal diffusivity ratio $\left(=\alpha_{\mathrm{w}} / \alpha_{\mathrm{f}}\right)$

$\tau \quad$ time

$\theta \quad$ angular coordinate

$v \quad$ kinematics viscosity

$\beta \quad$ coefficient of volumetric thermal expansion

$\xi \quad$ dimensionless logarithmic coordinate $(=\ln \mathrm{r})$

$\phi \quad$ dimensionless temperature $\left(=\mathrm{T}-\mathrm{T}_{\infty} / \mathrm{T}_{\mathrm{i}}-\mathrm{T}_{\infty}\right)$

$\psi \quad$ dimensionless stream function $\left(=\psi^{\prime} / \alpha_{\mathrm{f}}\right)$

$\Omega \quad$ dimensionless vorticity $\left(=-\Omega^{\prime} \mathrm{r}_{\mathrm{i}}{ }^{2} / \alpha_{\mathrm{f}}\right)$

\section{Subscript}

i inner surface of cylinder

o outer surface of cylinder

$\infty \quad$ at infinite distance from the cylinder surface

w cylinder wall

f fluid

\section{Abbreviations \\ Num. Numerical \\ Exp. Experimental \\ Theor. Theoretical}

\section{References}

[1] V.T. Morgan, The overall convective heat transfer from smooth circular cylinders, in: T.F. Irvine, J.P. Hartnett (Eds.), Advances in Heat Transfer, 11, 199-264, Academic Press, New York (1975).

[2] W. H. McAdams, Heat Transmission ( $3^{\text {rd }}$ edn). McGraw-hill, New York (1954).

[3] S. W. Churchill and H. H. S. Chu, Correlating equations for laminar and turbulent free convection from a horizontal cylinder, Int. J. Heat and Mass Transfer, 18(9-D), 1049-1053 (1975).

[4] T. H. Kuehn and R. J. Goldstein, Numerical solution to the Navier-Stokes equations for laminar natural convection about a horizontal isothermal circular cylinder, Int. J. Heat Mass Transfer 23, 971-979 (1980).

[5] Wang, R. Kahawita and T. H. Nguyen, Numerical computation of the natural convection flow about a horizontal cylinder using splines, Numer. Heat Transfer 17A, 191-215 (1990).

[6] P. Wang, R. Kahawita and D. L. Nguyen, Transient laminar natural convection from horizontal cylinders, Int. J. Heat and Mass Transfer, 34(6), 1429-1442 (1991).

[7] T. Fujii, M. Fujii and T. Honda, Theoretical and experimental study on free convection around a 
horizontal wire, J. Soc. Mech. Engrs 48(431), 1312-1320, (1982).

[8] T. Saitoh, T. Sajiki and K. Maruhara, Bench mark solutions to natural convection heat transfer problem around a horizontal circular cylinder, Int. J. Heat and Mass Transfer, 36(5), 1251-1259 (1993).

[9] B. Farouk, S. I. Guceri, Natural convection from a horizontal cylinder-laminar regime, ASME J. Heat Transfer, 103, 522-527 (1981).

[10]D. B. Ingham, Free-convection boundary layer on an isothermal horizontal cylinder, J. Appl. Mech. Phys. 29, 871-883 (1978).

[11]C. M. Vest and M. L. Lawson, Onset of convection near a suddenly heated horizontal wire, Int. J. Heat Mass Transfer 15, 1281-1283 (1972).

[12]L. Pera and B. Gebhart, Experimental observations of wake formation over cylindrical surfaces in natural convection flows, Int. J. Heat Mass Transfer 15, 175-177 (1972).

[13] J. R. Parsons, Jr. and J. C. Mulligan, Transient free convection from a suddenly heated horizontal wire, Trans. Am. Soc. Mech. Engrs, J. Heat Transfer 100, 423-428 (1978).

[14] J. R. Parsons, Jr. and J. C. Mulligan, Onset of natural convection from a suddenly heated horizontal cylinder, Trans. Am. Soc. Mech. Engrs, J. Heat Transfer 102, 636-639 (1980).

[15]R. E. Faw, R. P. H. Ismuntoyo and T. W. Lester, Transition from conduction to convection around a horizontal cylinder experiencing a ramp excursion in internal heat generation, Int. J. Heat Mass Transfer 27, 1087-1097 (1984).

[16] S. Ozgur Atayilmaz and Ismail Teke, Experimental and numerical study of the natural convection from a heated horizontal cylinder, Int. Comm. Heat Mass Transfer 36, 731-738 (2009).

[17]H. M. Badr, Heat transfer in transient buoyancy driven flow adjacent to a horizontal rod, Int. J. Heat Mass Transfer 30(10), 1997-2012 (1987).

[18]E. M. Sparrow and S. S. Kang, Two-dimensional heat transfer and critical radius results for natural convection about an insulated horizontal cylinder, Int. J. Heat and Mass Transfer 28(11), 2049-2060 (1985).
[19] S. C. Haldar, Conjugate analysis of heat transfer from a horizontal insulated cylinder, Int. Comm. Heat and Mass Transfer 30(1), 139-147 (2003).

[20] S. Yamamoto, D. Niiyama and B. R. Shin, A numerical method for natural convection and heat conduction around and in a horizontal circular pipe, Int. J. Heat and Mass Transfer 47, 5781-5792 (2004).

[21]M. Ait Saada, S. Chikh and A. Campo, Natural convection around a horizontal solid cylinder wrapped with a layer of fibrous or porous material, Int. J. Heat and Fluid Flow 28, 483-495 (2007).

[22] S. Ozgur Atayilmaz and Ismail Teke, Experimental and numerical study of the natural convection from a heated horizontal cylinder wrapped with a layer of textile material, Int. Comm. Heat and Mass Transfer 37(1), 58-67 (2010).

[23] S. Ozgur Atayilmaz, Demir Hakan and Agra Ozden, Numerical study of the natural convection around an isolated horizontal cylinder and determination of critical radius effect with a variable heat transfer coefficient, ASME Summer Heat Transfer Conference, San Francisco (2009).

[24]E. M. Sparrow, Reexamination and correction of the critical radius for radial heat conduction, A.I.Ch.E. Journal 16, 149 (1970).

[25] L. D. Simmons, Critical thickness of insulation accounting for variable convection and radiation loss, J. Heat Transfer 98, 150-152 (1976).

[26] R. T. Balmer, The critical radius effect with a variable heat transfer coefficient, A.I.Ch.E. Journal 24, 547-548 (1978).

[27] M.R. Kulkarni, Critical radius for radial heat conduction: a necessary criterion but not always sufficient, Applied Thermal Engineering 24, 967979, (2004).

[28] Patankar, S. V., Numerical heat transfer and fluid flow, Hemisphere Washinton, D. C., 1980.

[29] F. P. Incropera and D. P. Dewitt, Fundamentals of heat and mass transfer, $4^{\text {th }}$ ed. New York: Wiley publishing, (1996).

[30] S. J. Kline and F. A. McClintock, Describing uncertainties in single sample experiments, Mechanical Engineering 75(1), 3-8 (1953). 